secondary services. All clinicians will be familiar with such individuals, who present a therapeutic challenge where equipoise is acknowledged. One benefit of this research, therefore, is its potential to inform a nonpharmacological protocol of treatment, capitalising on the efficacy of cognitivebehavioural therapy in psychosis and emotional disorders.

Birchwood, M. (2003) Pathways to emotiona dysfunction in first-episode psychosis. British Journal of Psychiatry, 182, 373-375.

Rethink (2002) Reaching People Early. Kingston upon Thames: Rethink Publications.

M. Birchwood Birmingham Early Intervention Service, Harry Watton House, 97 Church Lane, Aston, Birmingham B6 5UG, and University of Birmingham, UK

The International Early Psychosis Association would like to contribute to the debate on early intervention (Pelosi/Birchwood, 2003).

First, the international network promoting reform in early psychosis is led by clinicians and academics who have a record of commitment to evidence-based medicine and leadership in scientific research. The attempt to discredit this network as mere evangelism does not bear scrutiny. However, successful reform in health care is always a blend of logic, evidence and advocacy. The latter is not only a legitimate but an essential element.

'We should be active and loud advocates of the mentally ill and be in the forefront of their battle to realise their rights. This might require that we relinquish some of our professional role and add some political activism to our daily chores - a sometimes difficult but now ever more necessary reorientation for doctors in general and psychiatrists in particular' (Sartorius, 1998).

Second, Dr Pelosi seriously underestimates the weakness of existing generic models of care for early psychosis patients and their families (Garety \& Rigg, 2001). Access to and quality of initial care for first-episode psychosis is poor in the UK setting, as it is in most affluent, developed countries. This indicates a structural as well as a funding problem. Services targeting 'serious and enduring mental illness' inevitably focus on the needs of 'prevalent' rather than 'incident' cases. The early intervention paradigm asserts that there is a need to subspecialise in relation to the needs of young early psychosis patients, both in terms of structure of the service and the content of interventions, according to a 'staging' model. This assertion has tapped into resistance to subspecialisation in general within psychiatry, which Dr Pelosi passionately expresses. However, excessive reliance on purely generic service models is not defensible and is bound to limit the quality of response in many areas of psychiatry. A balance should be sought.

Third, implementing overdue reforms inevitably creates secondary problems and 'perverse effects', which seem to lie at the heart of Dr Pelosi's concerns. Workforce supply, quality and morale are crucial issues. Without careful planning, there could indeed be adverse effects on pre-existing elements of the system. These second-order issues need to be tackled but do not seriously challenge the logic and urgent need for reform in early psychosis, and should not be allowed to delay or derail it. In the longer term, greater specialisation within an umbrella of integrated services is a pathway to better morale and quality. The successful emergence of other sub-specialty areas (e.g. old age psychiatry) illustrates this point. Looking further ahead, early intervention could ultimately represent a way station en route to a sub-specialty of youth psychiatry (McGorry \& Yung, 2003).

Fourth, the emerging early intervention services are targeted from first-episode psychosis onwards and do not specifically include the prodromal phase, which remains a research issue. There are genuine issues involved in sub-threshold detection of a low-incidence disorder and these remain to be solved. However, the caution required in extending intervention to potentially prodromal patients cannot be used as an argument for delaying intervention to people with clearly diagnosable first-episode psychosis.

Far from being wishful thinking, this reform process is already leading to improved short-term outcomes for young people with psychotic illness in many centres around the world (Edwards \& McGorry, 2002). The reform is delicately poised in the UK and there may well be secondary effects on mainstream systems, but these should not be seen as fatal flaws, rather as problems to be solved. In the UK setting, it is to be hoped that psychiatrists will play a leadership role in this vital endeavour, which should ultimately lead to a strengthening of the specialist mental health system. In other parts of the world we are looking to you to make a success of this important task and hope your pioneering reforms will help to guide our own efforts.

Edwards, J. \& McGorry, P. D. (2002) Implementing Early Intervention in Psychosis. A Guide to Establishing Early Psychosis Services. London: Martin Dunitz.

Garety, P. A. \& Rigg, A. (200I) Early psychosis in the inner city: a survey to inform service planning. Social Psychiatry and Psychiatric Epidemiology, 36, 537-544.

McGorry, P. D. \& Yung, A. R. (2003) Early intervention in psychosis: an overdue reform: an introduction to the Early Psychosis Symposium. Australian and New Zealand Journal of Psychiatry, 37, 393-398.

Pelosi, A./Birchwood, M. (2003) In debate: Is early intervention for psychosis a waste of valuable resources? British Journal of Psychiatry, 182, 196-198.

Sartorius, N. (1998) Stigma: what can psychiatrists do about it? Lancet, 352, 1058-1059.

P. D. McGorry On behalf of the Internationa Advisory Board, International Early Psychosis Association (IEPA), Locked Bag 10, Parkville, Victoria, Australia 3052. E-mail:

mcgorry@ariel.ucs.unimelb.edu.au

Author's reply: The advocacy and political activism of the International Early Psychosis Association has clearly been successful in the UK since teams for their narrow sub-specialty have been introduced despite widespread shortages of trained mental health professionals. General psychiatrists also consider themselves to be advocates for people with mental illness. They may not have the public relations skills of the early intervention movement but they believe that clinical experience and knowledge of epidemiology and health economics should be more important in determining health policy.

The most ambitious aim of the early intervention specialists has been to identify and treat people during a pre-psychotic phase of illness. There now seems to be unanimous agreement that any such attempts to prevent the onset of, for example, schizophrenia could only lead to more harm than good. The International Early Psychosis Association should return to users, carers, policy makers and members of the public whom they have influenced (Goode, 1999) and explain the epidemiological and clinical errors behind their previous dreams of primary prevention.

There should also be unanimous agreement with your earlier correspondent that provision of care to young people who have recently developed a psychotic illness is not 'rocket science' (Owen, 2003). I have read and re-read accounts of the clinical methods 
of the early intervention practitioners. They describe straightforward psychosocial and pharmacological therapies that should be used by all multidisciplinary teams. The only distinguishing feature is the subspecialists' touching faith in the effectiveness of antipsychotic medicines, which presumably arises from lack of prolonged experience with individual patients.

This inadequate experience of chronic illness is certain to lead to tragedies in the UK. The chosen remit of early intervention practitioners is to assist patients during the first 3 years of illness (Birchwood et al, 1998) - unless case-loads are high, when the 'critical period' can be reduced to 18 months (McGorry et al, 1999). When relapses occur, ordinary in-patient and community teams will, of course, have to pick up the pieces and I am in no doubt that they will be criticised for not being as attentive and caring as previous keyworkers.

Community mental health teams do not 'inevitably focus on the needs of "prevalent" rather than "incident" cases'. Those who are definitely - or probably, or possibly - in the early stages of psychosis are high in their list of priorities. Unlike Manchanda et al, they do not require 'controlled trials to assess the efficacy of early intervention'. These patients are unwell and they all require prompt and appropriate treatment. One of the most important tasks of consultant psychiatrists is to prioritise according to clinical need and it is frustrating when diversion of resources to highly protected teams makes difficult decisions even more painful. Your correspondents are shirking their responsibilities in depending on central planning to protect their case-loads (Milner, 2003; Owen, 2003). Valuable work has been done in this area (Kennedy \& Griffiths, 2001) and training would be available for any sub-specialist who returns to mainstream practice.

The introduction of early intervention teams in the UK should now be halted. This will provide an opportunity for proper scientific evaluation by comparing the processes and outcomes of care in areas where these teams have and have not been established. It will also free up some financial and human resources for serious hospital and community psychiatry.

Birchwood, M., Todd, P. \& Jackson, C. (1998) Early intervention in psychosis. The critical period hypothesis. British Journal of Psychiatry, 172 (suppl. 33), 53-59.

Goode, E. (1999) Doctors try a bold move against schizophrenia. New York Times, 7 December.
Kennedy, P. \& Griffiths, H. (200I) General psychiatrists discovering a new role for a new era ... and removing work stress. British journal of Psychiatry, I79, 283-285.

McGorry, P. D., Edwards, J. \& Pennell, K. (1999) Sharpening the focus: early intervention in the real world. In The Recognition and Management of Early Psychosis (eds P. D. McGorry \& H. J. Jackson). Cambridge: Cambridge University Press.

Milner, E. C. R. (2003) lnvest in CMHTs or subspecialist teams? British Journal of Psychiatry, eLetter, 4 March.

Owen, A. (2003) What is early intervention? (letter) British Journal of Psychiatry, 183, 562.

A. J. Pelosi Hairmyres Hospital, East Kilbride G75 8RG, UK. E-mail:

anthonypelosi@compuserve.com

\section{Testosterone and psychosis}

Increased testosterone may be the cause of the finding of Sundquist et al (2004) that 'A high level of urbanisation is associated with increased risk of psychosis and depression for both women and men'. Two hypotheses are required to explain this.

It is my hypothesis (Howard, 2001a) that human evolution is driven by testosterone. Based on this, I suggest the 'secular trend', the increase in size and early puberty of children, is actually an increase in the percentage of individuals of higher testosterone. The trend may actually be a change in percentage of individuals within our populations and their 'characteristics' may also be increasing. This phenomenon occurs when a 'feed and breed' environment occurs. In these situations, individuals of higher testosterone, both men and women, will increase more rapidly than those of lower testosterone over time. (Individuals of higher testosterone are more aggressive and sexual.) Urban areas are 'feed and breed' centres; I suggest urban centres are areas of higher testosterone.

I hypothesise that dehydroepiandrosterone (DHEA) is directly involved in growth and development, and subsequent maintenance, of all tissues, especially the brain. (The large brain of mammals may have resulted from an evolutionary increase in DHEA; Howard, 2001b.) Numerous reports of beneficial effects of DHEA on neurons and tissue-level structures of the brain exist in the literature. I have suggested in the past that depression and schizophrenia, among other mental disorders, result from low DHEA during growth and development, subsequently exposed by adverse circumstances during maintenance.
In depression and schizophrenia DHEA is low. Two other hormones may adversely affect the function or availability of DHEA: cortisol and testosterone. Over the past few years a connection with low DHEA, along with increased cortisol, has been demonstrated regarding depression. It is known that schizophrenia is often characterised as resulting from a non-causal, but significant, stressful event (cortisol) usually beginning in the late teens or early twenties (testosterone of puberty, in men and women, along with the natural decline of DHEA which begins at around age 20). In individuals of low DHEA, increased cortisol and testosterone may expose underlying, silent pathology.

Therefore, I suggest that increased rates of psychoses and depression in urban areas may be the product of increased stress and testosterone in both men and women. As suggested above, the secular trend may be due to increasing numbers of individuals of higher testosterone. This increase in these individuals of higher testosterone, along with increasing stress of urbanisation, may account for the findings of Sundquist $e t a l$, as well as reports of recent increases in these mental disorders.

Howard, J. (200la) Androgens in human evolution. A new explanation of human evolution. Rivista di Biologia, 94, 345-362.

Howard, J. (2001b) Hormones in mammalian evolution. Rivista di Biologia, 94, 177-183.

Sundquist, K., Frank, G. \& Sundquist, J. (2004) Urbanisation and incidence of psychosis and depression. Follow-up study of 4.4 million women and men in Sweden. British Journal of Psychiatry, 184, 293-298.

J. M. Howard 1037 North Woolsey Avenue, Fayetteville, Arkansas 7270I-2046, USA. E-mail: jmhoward@anthropogeny.com

\section{Neurosurgery for mental disorder}

Dr Persaud provides an ardent but ultimately flawed argument in favour of allowing neurosurgery for mental disorder (NMD) to die out (Persaud/Crossley \& Freeman, 2003).

Patients who are considered for NMD are among the most severely ill and disabled who come into contact with any branch of the medical profession, and such presentations merit conceptualisation as rather more than having 'psychological problems'.

It is also disingenuous to argue that 'psychosurgery' (sic) tries to locate complex psychiatric disorders in 'one so-called "abnormal" brain region'. Such hangovers 